\title{
NMR metabolic profiling of the liver following administration of alcohol and the mushroom Ganoderma lucidum in rats
}

\author{
M.S. Krestina ${ }^{1,3}$, O.B. Shevelev² ${ }^{2}$ I.V. Koptyug ${ }^{1}$, L.A. Gerlinskaya ${ }^{2}$, S.E. Peltek ${ }^{2}$, A.E. Akulov ${ }^{2}$ \\ ${ }^{1}$ International Tomography Center of the Siberian Branch of the Russian Academy of Sciences, Novosibirsk, Russia \\ 2 Institute of Cytology and Genetics SB RAS, Novosibirsk, Russia \\ ${ }^{3}$ Novosibirsk State University, Novosibirsk, Russia
}

We have evaluated the efficiency of a metabonomic approach to metabolic phenotyping and detection of early metabolic changes under a toxic influence. For this purpose, a metabolic profiling of rat liver was performed with ${ }^{1} \mathrm{H}$ NMR spectroscopy. Rat tissues from animals in three groups were analyzed. Group C consisted of control animals; animals in group $A$ received alcohol repeatedly ( $15 \%$ ethanol); and animals in group $A+R$ received alcohol in combination with a hepatoprotective herbal medicine (Reishi, Ganoderma lucidum) repeatedly. Noteworthy, alcohol consumption did not cause pathological changes, but stimulated hepatocyte proliferation. Our data suggest that changes in metabolite concentrations in A represent a typical metabolic response to alcohol consumption, namely decrease in glycine, leucine, isoleucine, valine, choline and lactate content, and increase in TMAO content. Treatment with Reishi $(A+R)$ had positive effects, in that it restored the levels of glycine, valine and TMAO. Furthermore, increase in NAD, ATP, UTP, succinate, pyranose, and acetate concentrations was observed in $A+R$. A correlation was found between the valine, isoleucine, lactate, choline, and pyranose content and the number of binuclear hepatocytes. Binuclear hepatocytes indicate proliferative activity, and the concentration of the metabolites participating in the formation of new hepatic cells decreases. Thus, the study of liver tissues by ${ }^{1} \mathrm{H}$ NMR spectroscopy allows for detection of early changes in metabolite concentrations following chronic consumption of alcohol at insignificant doses. Consequently, ${ }^{1} \mathrm{H}$ NMR spectroscopy can serve as a promising approach to detecting alcohol-related liver pathologies and assessing the efficiency of the therapy used.

Key words: Sprague-Dawley rats; liver; alcohol; Ganoderma lucidum; ${ }^{1} \mathrm{H}$ NMR spectroscopy; in vitro; metabonomics; diagnosis of early metabolic disorders.

\section{Возможности высокотехнологичного фенотипирования методом спектроскопии ЯМР на примере метаболического отклика печени крыс на воздействие алкоголя и Рейши}

М.С. Крестина ${ }^{1,3}$, О.Б. Шевемев ${ }^{2}$, И.В. Коптюг ${ }^{1}$,

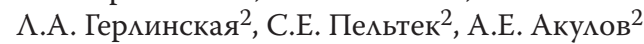

\footnotetext{
${ }^{1}$ Учреждение Российской академии наук Институт «Международный томографический центр» СО РАН, Новосибирск, Россия

2 Федеральное государственное бюджетное научное учреждение «Федеральный исследовательский центр Институт цитологии и генетики Сибирского отделения Российской академии наук», Новосибирск, Россия 3 Федеральное государственное автономное образовательное учреждение высшего образования «Новосибирский национальный исследовательский государственный университет», Новосибирск, Россия
}

Для оценки эффективности спектроскопии протонного ядерно-магнитного резонанса ('Н ЯМР) как метода метаболомного фенотипирования и метода детектирования ранних метаболических изменений при токсических воздействиях было проведено метаболическое профилирование печени крыс. Образцы тканей были взяты у трех групп крыс: группа К - контрольные животные; группа А - животные, получавшие многократно 15-процентный раствор алкоголя, прием которого не вызывал патологических изменений печени, но стимулировал пролиферацию гепатоцитов, и алкоголя в сочетании с растительным гепатопротекторным препаратом Рейши, Ganoderma lucidum, (группа A + P). Как следует из полученных результатов, изменения концентрации метаболитов в печени, наблюдаемые в группе A, отражали типичную метаболическую реакцию на прием алкоголя и выражались в снижении содержания глицина, лейцина, изолейцина, валина, холина и лактата, а также в повышении уровня ТМАО. При приеме Рейши у крыс группы А + восстанавливалась концентрация глицина, валина и ТМАО. Кроме того, в группе A+P было отмечено увеличение относительно контроля концентрации НАД, АТФ, УТФ, сукцината, пиранозы и ацетата. Индивидуальные вариации содержания валина, изолейцина, лейцина, лактата, холина и пиранозы коррелировали с числом двуядерных гепатоцитов как индикатором пролиферативной активности. Таким образом, исследование тканей печени методом спектроскопии ЯМР ${ }^{1} \mathrm{H}$ позволяет выявить ранние отклонения уровня метаболитов при хроническом потреблении небольших доз алкоголя и может быть перспективным подходом как для диагностического выявления алкогольного повреждения 
печени, так и для оценки эффективности применяемой лекарственной терапии.

Ключевые слова: крысы Sprague-Dawley; печень; алкоголь; Ganoderma lucidum; спектроскопия ЯМР ${ }^{1} \mathrm{H}$; in vitro; метабономика; диагностика ранних метаболических нарушений.

\begin{abstract}
HOW TO CITE THIS ARTICLE?
Krestina M.S., Shevelev O.B., Koptyug I.V., Gerlinskaya L.A., Peltek S.E., Akulov A.E. NMR metabolic profiling of the liver following administration of alcohol and the mushroom Ganoderma lucidum in rats. Vavilovskii Zhurnal Genetiki i Selektsii - Vavilov Journal
\end{abstract} of Genetics and Breeding. 2015;19(4):499-504. DOI 10.18699/VJ15.067

\title{
КАК ЦИТИРОВАТЬ ЭТУ СТАТЬЮ?
}

Крестина М.С., Шевелев О.Б., Коптюг И.В., Герлинская Л.А., Пельтек С.Е., Акулов А.Е. Возможности высокотехнологичного фенотипирования методом спектроскопии ЯМР на примере метаболического отклика печени крыс на воздействие алкоголя и Рейши. Вавиловский журнал генетики и селекции. 2015;19(4):499-504. DOI 10.18699/VJ15.067

A лкоголь можно отнести к одному из наиболее распространенных агентов токсической нагрузки на организм человека. Воздействие алкоголя сказывается на обменных процессах, протекающих в организме, что может приводить к нарушению нормального функционирования как отдельных органов, так и целых систем. Известно, что наибольшую токсическую нагрузку при употреблении алкоголя испытывает печень как основной орган детоксикации (Lieber, 2004). Повреждение печени может происходить не только при единовременном воздействии большой дозы алкоголя, но и при хроническом потреблении малых доз (Romero-Martínez, Moya-Albiol, 2013). Подобное воздействие алкоголя способно приводить к жировой дистрофии печени, фиброзу и в итоге к алкогольному циррозу печени и даже гепатоцеллюлярной карциноме (Bruha et al., 2012). Важно отметить, что до этапа алкогольного цирроза повреждения печени носят обратимый характер, что актуализирует развитие методов ранней диагностики повреждений органа.

Вместе с тем наравне с развитием методов выявления патологии и определения ее стадии остро стоит вопрос развития методов контроля эффективности лечебных и профилактических средств. Основными требованиями к таким методам служат малая инвазивность и высокая информативность. К ним можно отнести метод спектроскопии ЯМР. В настоящее время ведутся работы, направленные на применение спектроскопии ЯМР для диагностики повреждений печени или мозга при анализе образцов крови и/или мочи (Gika, Wilson, 2014). Это возможно благодаря тому, что ЯМР позволяет получать количественную информацию о большом числе метаболитов, вовлеченных в разные метаболические пути. Что, в свою очередь, помогает найти критические точки в обменных процессах, воздействие на которые может минимизировать негативное влияние алкоголя или эффективно корректировать уже сложившееся метаболическое нарушение. Вопрос применения спектроскопии ЯМР тканей печени в качестве диагностического метода остается дискуссионным и открытым, но на данном этапе развития он может выступать в роли технологического сопровождения при проверке эффективности экспериментальных препаратов, проходящих доклинические испытания на животных, а также при фенотипировании генетических линий животных, склонных к врожденным нарушениям метаболизма.

Прекращение потребления алкоголя и назначение специальной диеты на поздних стадиях развития патологии не приводят к выздоровлению, для этого требуется эффективная лекарственная терапия. Для восстановления нормальной функции печени разрабатываются препараты, обладающие гепатопротекторными свойствами. Большинство из них направлено на восстановление мембран клеток (фосфолипиды) или компенсацию отдельных метаболитов, вовлеченных в процессы детоксикации. Вместе с тем в качестве гепатопротекторных не раз использовались препараты растительного происхождения (Kushnerova et al., 2014; Fehér et al., 2015): экстракт древесины маакии амурской (Maackiae amurensis ligni), экстракт плодов расторопши пятнистой (Silybi mariani fructuum). Эффективность таких препаратов может заключаться в содержании в экстрактах целого комплекса биологически активных компонентов. К ним относится Рейши (в соответствии с названием, принятым в китайской медицине), который изготавливается из экстракта гриба Ganoderma lucidum. Рейши успешно используется для лечения хронических заболеваний печени различной этиологии. Предполагается, что защиту от повреждений печени, вызванных токсинами или этанолом, обеспечивают входящие в состав Рейши тритерпеноиды и полисахариды (Gao et al., 2003). Тритерпеноиды обладают антиоксидантной активностью и способны связывать свободные радикалы (Wang et al., 2000; Shi et al., 2008), а полисахариды эффективно ингибируют развитие окислительного стресса в мозге при гипоксии и реоксигенации (Zhao et al., 2004). Терапевтическая эффективность Рейши была также продемонстрирована на моделях гепатостеатоза (Shieh et al., 2001) и экспериментально индуцированного фиброза печени (Wu et al., 2010).

В данном исследовании была проведена in vitro спектроскопия ЯМР ${ }^{1} \mathrm{H}$ тканей печени крыс линии SpragueDawley после хронического потребления небольших доз алкоголя (15\%-й этанол) и совместного приема алкоголя с Рейши. Данные спектроскопии in vitro были сопоставлены с полученными на тех же животных показателями пролиферативной активности печени (Shevelev et al., 2015).

\section{Материалы и методы}

Моделирование хронического воздействия алкоголя и лекарственная терапия выполнены на 29 лабораторных крысах аутбредной линии Sprague-Dawley в возрасте 8-9 нед на базе Центра генетических ресурсов лабораторных животных ИЦиГ CO РАН (RFMEFI61914Х0005 и RFMEFI62114X0010). Животных содержали по одному 
в индивидуально вентилируемых клетках высотой 20,5 см и площа-

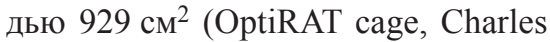
River Laboratories, Франция) при свободном доступе к воде и гранулированному корму для лабораторных грызунов SPF-категории «Чара» (ЗАО «Ассортимент-Агро», Россия), искусственном фотопериоде 14С:10T, температуре $22-24{ }^{\circ} \mathrm{C}$ и влажности 40-50 \%. В качестве подстилочного материала использовались сухие обеспыленные опилки (ООО «Альбион», г. Новосибирск). Корм и подстилку перед использованием автоклавировали при температуре $121{ }^{\circ} \mathrm{C}$. Для поения животных использовали деионизированную воду, полученную на установке Millipore, после обогащения минеральной добавкой «Северянка» (ООО «Эко-Проект», г. Санкт-Петербург).

В качестве лекарственной терапии в данной работе использовали экстракт гриба Рейши, который относится к виду Ganoderma lucidum. Данный гриб был собран в Алтайском крае, высушен и измельчен до размера частиц не более 150 мкм (MAN-30, ЗАO MVM, Россия). Затем сухие измельченные грибы разводили в 1 мл деионизированной воды, полученной на установке Millipore. Необходимая концентрация Рейши составляла 100 мг/кг (Kwon, Kim, 2011), поскольку средний вес животных на момент начала исследования составлял 330 г, концентрация грибов в суспензии выбрана равной 33 мг/мл. Суспензия приготавливалась ежедневно непосредственно перед использованием, затем препарат вводился с помощью желудочного зонда.

Животные были разделены на три группы:

1) экспериментальная - алкоголь + Рейши: животным $(n=9)$ внутрижелудочно вводили по 1 мл раствора Рейши каждый день. С 6-го по 26-й дни эксперимента животные получали $15 \%$-й этанол. Для этого в начале темнового периода поилки с водой из клеток заменяли на поилки с 15 \%-м этанолом. Через 16 ч животным возвращали воду и убирали этанол. Потребление воды и алкоголя измеряли ежесуточно взвешиванием поилок;

2) экспериментальная группа - алкоголь: вместо Рейши животные $(n=10)$ получали внутрижелудочно

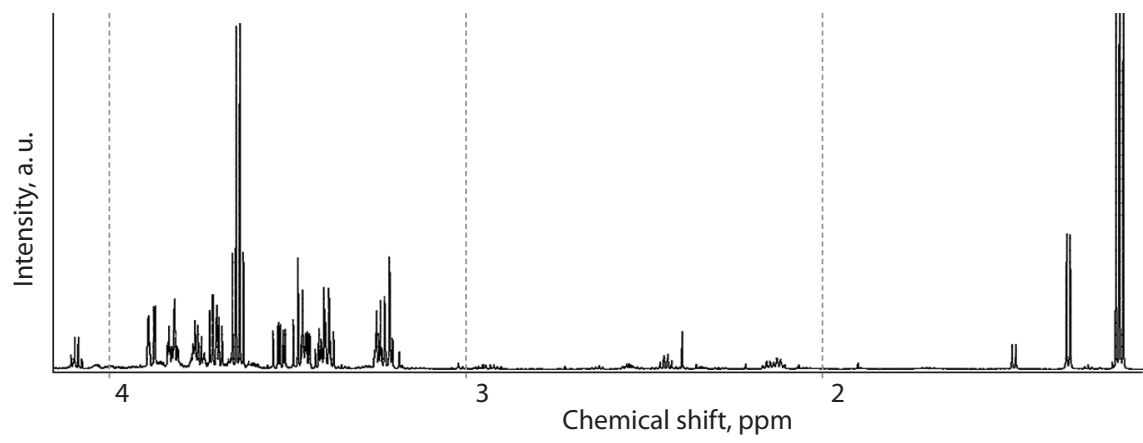

${ }^{1} \mathrm{H}$ NMR spectrum of the rat liver metabolite extract at $700 \mathrm{MHz}$.

воду. С 6-го по 26-й дни эксперимента, как и в предыдущей группе, животные получали 15 \%-й этанол, который давали в соответствии с описанным выше протоколом;

$3)$ контрольная группа: животные $(n=10)$ получали с 1-го по 6-й дни эксперимента воду внутрижелудочно, с 6-го по 26-й дни - в поилках, которые меняли, но в них была только вода.

На 27-й день эксперимента крысы были умерщвлены, печень извлекали и замораживали при $-80{ }^{\circ} \mathrm{C}$ (кельвинатор, SANYO MDF-594) для дальнейшего анализа с помощью in vitro спектроскопии ЯMP ${ }^{1} \mathrm{H}$. Непосредственно перед спектроскопией образцы размораживали и подготавливали в соответствии со следующим протоколом: 1) гомогенизация ткани (гомогенизатор Поттера-Эльвейема, 70 мг ткани, 700 мкл 80 \%-го этанола); 2) обработка ультразвуком (ультразвуковой прибор QSonica q700, 300 Вт, 5 мин); 3) перемешивание на шейкере (BioSan Vortex V-1 plus, 5 мин); 4) центрифугирование (EPPENDORF Centrifuge 5810R, 30 мин, $40{ }^{\circ} \mathrm{C}, 13200$ об./мин); 5) отделение части пробы, не выпавшей в осадок; 6) удаление водонерастворимых веществ; для лучшего разделения на фракции к этанольной экстракции добавляли хлороформ (Sigma-Aldrich, США) и воду (Millipore) в пропорциях $1: 1 ; 7)$ центрифугирование (EPPENDORF Centrifuge 5810R, 30 мин, $40{ }^{\circ} \mathrm{C}, 13200$ об./мин); 8) повторение стадий (5), (6), (7); 9) отделение верхней водорастворимой фракции; 10) дегидратация на вакуумном испарителе (RVC 2-25 CD plus «Christ», 24 ч, $250{ }^{\circ} \mathrm{C}, 1000$ об./мин); 11) после дегидратации вещество растворяли в дейтерированной воде (99,9\%, Sigma-Aldrich, 600 мкл), затем перемешивали на шейкере (BioSan Vortex V-1 plus 5 мин) и обрабатывали ультразвуком (ультразвуковая ванна Сапфир, 20 мин).

Спектроскопия ЯМР ${ }^{1} \mathrm{H}$ выполнена на высокопольном спектрометре Bruker Avance III 700 МГц, оборудованном криодатчиком Cryoprobe Prodigy. Для получения спектров ЯМР ${ }^{1} \mathrm{H}$ использовалась одноипульсная последовательность (90 импульс длительностью 7,7 мкс), после чего записывался спад свободной индукции, задержка между накоплениями составляла 17 с. Продолжительность накопления составила 1 ч 5 мин, включала 4 пустых скана и 128 сканов накопления. На рисунке приведен типичный спектр метаболитов печени.

С помощью баз данных Biological Magnetic Resonance Data Bank, Human Metabolome Data Base и литературного анализа (Roslundet et al., 2008; Psychogios et al., 2011; Feng et al., 2013) путем сравнения спектров, полученных в отдельности для каждого вещества из баз данных, и экспериментальных (программа, используемая для сравнения, написана на Delphi И.В. Коптюгом) были идентифицированы метаболиты, соответствующие наиболее интенсивным пикам в спектрах ЯМР. Помимо сравнения с базами данных, для проверки часть метаболитов (аланин, валин, глицин, глутатион, глутамин, изолейцин, креатин, лейцин, пролин, фенилаланин, холин, тирозин, D-глюкоза и НАД, SigmaAldrich) добавляли в исследуемый образец для установления концентрационной зависимости, что служило критерием достоверности соотнесения пиков.

Для определения концентрации было проведено суммирование площадей пиков, относящихся к каждому из выделенных метаболитов. Полученные в хо- 
Metabolite content in the livers of control and experimental rat groups (a.u.)

\begin{tabular}{|c|c|c|c|}
\hline Metabolite & Control $(n=10)$ & Alcohol $(n=10)$ & Alcohol+Reishi $(n=9)$ \\
\hline ATP & $9.5 \pm 0.8$ & $9.7 \pm 0.7$ & $11.5 \pm 1.0$ \\
\hline Arginine & $5.9 \pm 0.7$ & $6.2 \pm 0.3$ & $6.9 \pm 0.2$ \\
\hline Acetate & $6.6 \pm 0.5$ & $6.2 \pm 0.4$ & $8.2 \pm 0.9^{\#}$ \\
\hline Alanine & $30.0 \pm 0.7$ & $26.7 \pm 1.2$ & $28.1 \pm 2.0$ \\
\hline Valine & $14.7 \pm 0.6$ & $11.8 \pm 0.6^{*}$ & $12.8 \pm 0.6$ \\
\hline Histidine & $3.2 \pm 0.3$ & $3.2 \pm 0.2$ & $3.5 \pm 0.1$ \\
\hline Glycine & $32.2 \pm 1.9$ & $26.2 \pm 1.7^{*}$ & $31.2 \pm 2.1$ \\
\hline Glutathione & $2.7 \pm 0.2$ & $3.1 \pm 0.2$ & $2.8 \pm 0.2$ \\
\hline Glutamine & $59.2 \pm 2.7$ & $54.9 \pm 7.0$ & $63.5 \pm 1.9$ \\
\hline Glutamate & $13.2 \pm 1.0$ & $13.8 \pm 0.5$ & $14.4 \pm 0.8$ \\
\hline Isoleucine & $9.8 \pm 0.4$ & $7.6 \pm 0.3^{*}$ & $8.3 \pm 0.5^{*}$ \\
\hline Creatine & $5.0 \pm 0.6$ & $4.3 \pm 0.4$ & $4.5 \pm 0.4$ \\
\hline Lactate & $292.1 \pm 9.5$ & $248.0 \pm 6.9^{*}$ & $249.4 \pm 9.2^{*}$ \\
\hline Leucine & $8.1 \pm 0.3$ & $6.7 \pm 0.2^{*}$ & $6.7 \pm 0.3^{*}$ \\
\hline Myo-inositol & $41.9 \pm 2.4$ & $40.3 \pm 2.5$ & $42.5 \pm 3.1$ \\
\hline NAD & $6.2 \pm 0.4$ & $6.8 \pm 0.6$ & $7.9 \pm 0.4^{*}$ \\
\hline Proline & $8.6 \pm 0.7$ & $8.2 \pm 0.4$ & $8.8 \pm 0.4$ \\
\hline Succinate & $35.9 \pm 2.6$ & $31.9 \pm 0.8$ & $40.0 \pm 2.9^{\#}$ \\
\hline TMAO & $123.5 \pm 14.2$ & $194.4 \pm 10.1^{*}$ & $148.3 \pm 15.8^{\#}$ \\
\hline UTP & $1.2 \pm 0.3$ & $1.2 \pm 0.2$ & $3.1 \pm 0.8^{* \#}$ \\
\hline Phenylalanine & $4.8 \pm 0.4$ & $4.0 \pm 0.2$ & $4.9 \pm 0.4$ \\
\hline Fumaric acid & $1.3 \pm 0.2$ & $1.4 \pm 0.1$ & $1.3 \pm 0.2$ \\
\hline Choline & $25.4 \pm 1.8$ & $18.0 \pm 1.2^{*}$ & $18.3 \pm 1.4^{*}$ \\
\hline a--pyranose & $161.8 \pm 3.1$ & $158.9 \pm 3.3$ & $171.0 \pm 4.2^{\#}$ \\
\hline$\beta$-hydroxybutyrate & $1.9 \pm 0.1$ & $1.9 \pm 0.1$ & $2.0 \pm 0.1$ \\
\hline a-hydroxybutyrate & $4.4 \pm 0.3$ & $3.7 \pm 0.2$ & $4.2 \pm 0.3$ \\
\hline
\end{tabular}

* Significantly different from controls: $p<0.05$; " significant difference between "alcohol" and "alcohol + Reishi" groups: $p<0.05$. LSD-test was used in both cases.

де интегрирования данные обрабатывались с помощью пакета статистических методов Statistica 6.0. Для установления принадлежности экспериментальных данных к нормальному распределению использовался критерий Колмогорова-Смирнова. Данные были представлены в виде средних величин со среднеквадратичными ошибками. Установление достоверных различий средних для метаболитов между группами проведено с помощью множественного сравнения средних (LSD-тест). Взаимозависимость между содержанием метаболитов и числом двуядерных гепатоцитов оценивали по коэффициенту ранговой корреляции Спирмена.

\section{Результаты}

Хроническое потребление небольших доз алкоголя приводило к снижению уровня ряда аминокислот, валина, глицина, изолейцина, лейцина, а также лактата, холина, и повышению уровня ТМАО (таблица). Прием Рейши на фоне потребления алкоголя восстанавливал уровни валина, глицина, ТМАО, при этом уровни изолейцина, лейцина, лактата и холина оставались измененными относительно контроля. Вместе с тем в группе алкоголь + Рейши отмечалось увеличение, в сравнении с контролем, НАД, АТФ, УТФ, сукцината, пиранозы и ацетата.

\section{Обсуждение}

Проведенный ранее анализ показал, что использованная в работе доза алкоголя не вызывала патологических изменений печени, а лишь стимулировала процессы пролиферации как адаптивную реакцию органа на повышенную функциональную (в данном случае детоксицирующую) нагрузку (Shevelev et al., 2015). Вместе с тем даже при столь умеренной дозе алкоголя методом спектроскопии ЯМР ${ }^{1} \mathrm{H}$ были установлены существенные изменения в содержании ряда метаболитов печени. Прежде всего, обращает на себя внимание падение концентрации ряда аминокислот: глицина, лейцина, изолейцина и валина, три из которых (лейцин, изолейцин и валин) относятся к незаменимым аминокислотам с разветвленными цепочками - BCAA (Branched-Chain Amino Acids). Как известно, 
ВСАА являются исходным продуктом, необходимым для синтеза белка, субстратом для выработки энергии или синтеза иных аминокислот, в особенности глутамина и аланина, а также участвуют в сжигании излишних жиров за счет повышения лептина в адипоцитах (Nelson, Cox, 2008). Пониженный уровень этих аминокислот под влиянием алкоголя может быть трактован в пользу предположения о расходовании их на синтез белка, поскольку, как показали гистологические препараты печени исследованных животных, на этой стадии происходит увеличение числа двуядерных гепатоцитов (Shevelev et al., 2015). Вовлеченность данных аминокислот в процесс пролиферации подтверждается тем, что у крыс, получавших алкоголь, отмечены статистически значимые коэффициенты корреляции с числом двуядерных гепатоцитов для содержания в печени изолейцина $(r=-0,51, p<0,05)$ и лейцина $(r=-0,56, p<0,05)$, а для крыс, получавших алкоголь и Рейши, - валина $(r=-0,63, p<0,05)$ и изолейцина $(r=-0,71, p<0,01)$.

Усиленное деление клеток приводит к увеличению размеров печени - это приспособительная реакция организма в борьбе с длительной токсической нагрузкой, поскольку имеющейся емкости механизмов, способных нейтрализовать определенное количество этанола в единицу времени, становится недостаточно. Подобное снижение концентрации аминокислот также продемонстрировано в работах с хроническим воздействием больших доз алкоголя (Jang et al., 2012; Shayakhmetova et al., 2015). При этом в ряде работ показано положительное влияние на метаболизм печени увеличения в рационе питания ВСАА (Malaguarnera et al., 2009; Kato et al., 2013).

Еще одним метаболитом, концентрация которого снизилась в ответ на воздействие алкоголя, является холин, участвующий в синтезе фосфолипидов клеточных мембран. Уменьшение холина может свидетельствовать о повышенном запросе на него в организме при активном клеточном делении (Bollard et al., 2010), что хорошо согласуется с отрицательной корреляцией между уровнем холина в печени и числом двуядерных гепатоцитов в группах крыс, получавших алкоголь $(r=-0,61, p<0,05)$ и алкоголь в сочетании с Рейши $(r=-0,59, p<0,05)$.

В группах животных, получавших алкоголь и алкоголь + Рейши, наблюдается уменьшение концентрации лактата, уровень которого отрицательно коррелирует с числом двуядерных гепатоцитов: $r=-0,61(p<0,05)$ для группы алкоголь и $r=-0,50(p<0,05)$ - для группы алкоголь + Рейши. Этот факт отражает расходование лактата на синтез глюкозы через превращение в пируват, который в процессе глюконеогенеза синтезируется в глюкозу. Так как концентрация лактата уменьшается, то нужно рассматривать его участие в глюконеогенезе, но известно, что потребление этанола ингибирует этот процесс на 45 \% (Siler et al., 1998). Помимо литературных данных, в нашем исследовании также не наблюдается повышения концентрации $\alpha$-пиранозы. Таким образом, нужно рассматривать другие метаболические пути, в которых участвует пируват, являющийся промежуточным звеном многих процессов. Он может перейти в ацетил-КоА, который участвует в цикле Кребса, либо служит отправной точкой в синтезе жирных кислот и кетоновых тел. Также он может расходоваться на образование оксалоацетата или малата. Так как изменение лактата однонаправленно с изменением холина и $\alpha-$-гидроксибутирата, то можно предположить, что уменьшение лактата приводит к увеличению ацетил-КоА, синтезу и накоплению жирных кислот в печени. Такое же изменение уровня лактата при воздействии алкоголя было продемонстрировано в работе Nicholas с соавт. (2008).

Еще одно обстоятельство, которое следует рассматривать при анализе in vitro метаболитов энергетического обмена (лактат, НАД, УТФ и др.), связано с их чрезвычайно высокой динамичностью, в частности активация гликолиза и соответствующее увеличение концентрации лактата в тканях развиваются до значимых уровней в течение нескольких секунд. Поэтому при большей интенсивности энергообмена можно наблюдать увеличение уровня лактата, обусловленное временем от момента забоя животного до помещения органа в холод.

Единственным увеличившим свою концентрацию метаболитом при воздействии алкоголя стал ТМАО. Р. Коэт и его коллеги провели исследование (Koeth et al., 2013), в ходе которого животных кормили пищей, обогащенной TMАО. В результате было обнаружено, что ТМАО изменяет метаболизм холестерина в кишечнике, печени и стенке артерии. В присутствии ТМАО метаболизм холестерина увеличивается и происходит его повышенное накопление. При этом показано, что чрезмерное употребление продуктов с большим содержанием ТМАО (морепродукты, яйца, красное мясо, соя, некоторые энергетические напитки), а также его предшественников, карнитина или лецитина, может привести к формированию атеросклеротических бляшек (Tang et al., 2013). Это позволяет сделать вывод о том, что избыток ТМАО может приводить к накоплению жиров.

Сочетанный прием алкоголя и Рейши поддерживает концентрацию ТМАО, глицина и валина на уровне контрольных значений. Подобный эффект не может быть объяснен увеличенным поступлением этих веществ в организм в составе Рейши. Хотя есть работы, показывающие наличие целого ряда аминокислот в экстракте гриба Ganoderma lucidum (Wen et al., 2010), содержание их низкое, а количество экстракта, вводимого животным, мало и в сравнении с аминокислотами пищи, доступной животным в эксперименте, и составляет отношение $1: 5000$. Подобное влияние, однако, можно объяснить повышением в тканях печени при приеме Рейши таких энергетических субстратов, как НАД, УТФ, сукцинат и $\alpha$-пираноза, что, в свою очередь, может снижать пролиферативную активность гепатоцитов (Shevelev et al., 2015).

Таким образом, наше исследование демонстрирует возможность обнаружения методом in vitro спектроскопии ЯМР ${ }^{1} \mathrm{H}$ раннего изменения метаболического профиля печени при длительном воздействии небольших доз алкоголя. Также при помощи данного метода удалось установить положительные эффекты гепатопротекторного препарата растительного происхождения Рейши. Его прием приводит к частичному восстановлению метаболических отклонений, возникших при хроническом воздействии алкоголя. Полученные данные открывают перспективы применения спектроскопии ЯМР для провер- 
ки эффективности экспериментальных препаратов, проходящих доклинические испытания на животных, а также при фенотипировании генетических линий животных, склонных к врожденным нарушениям метаболизма.

\section{Acknowledgments}

This work was done as stipulated in Budget Project VI.53.2.1 and was supported by Project 14-35-00020 of the Russian Science Foundation.

\section{Conflicts of interest}

The authors declare no conflicts of interest.

\section{References}

Bollard M.E., Contel N.R., Ebbels T.M., Smith L., Beckonert O., Cantor G.H., Lehman-McKeeman L., Holmes E.C., Lindon J.C., Nicholson J.K., Keun H.C. NMR-based metabolic profiling identifies biomarkers of liver regeneration following partial hepatectomy in the rat. J. Proteome Res. 2010;9(1):59-69. DOI: 10.1021/pr900200v

Bruha R., Dvorak K., Petrtyl J. Alcoholic liver disease. World. J. Hepatol. 2012;4(3):81-90. DOI: 10.4254/wjh.v4.i3.81

Fehér P., Ujhelyi Z., Vecsernyés M., Fenyvesi F., Damache G., Ardelean A., Costache M., Dinischiotu A., Hermenean A., Bácskay I. Hepatoprotective effects of a self-micro emulsifying drug delivery system containing Silybum marianum native seed oil against experimentally induced liver injury. Pharmazie. 2015;70(4):231-238. DOI: $10.1691 / \mathrm{ph} .2015 .4146$

Feng J., Isern N.J., Burton S.D., Zhi Hu J. Studies of secondary melanoma on C57BL/6J mouse liver using ${ }^{1} \mathrm{H}$ NMR metabolomic. Metabolites. 2013;3(4):1011-1035. DOI: 10.3390/metabo3041011

Gao Y., Zhou S., Jiang W., Huang M., Dai X. Effects of ganopoly (a Ganoderma lucidum polysaccharide extract) on the immune functions in advanced-stage cancer patients. Immunol. Invest. 2003;32(3):201-215. DOI: 10.1081/IMM-120022979

Gika H.G., Wilson I.D. Global metabolic profiling for the study of alcohol-related disorders. Bioanalysis. 2014;6(1):59-77. DOI: 10.4155/ bio.13.301

Jang Z.H., Chung H.C., Ahn Y.G., Kwon Y.K., Kim J.S., Ryu J.H., Ryu Do H., Kim C.H., Hwang G.S. Metabolic profiling of analcoholic fatty liver in zebrafish (Danio rerio). Mol. Biosyst. 2012;8(7):20012009. DOI: $10.1039 / \mathrm{c} 2 \mathrm{mb} 25073 \mathrm{j}$

Kato A., Tanaka H., Kawaguchi T., Kanazawa H., Iwasa M., Sakaida I., Moriwaki H., Murawaki Y., Suzuki K., Okita K. Nutritional management contributes to improvement in minimal hepatic encephalopathy and quality of life in patients with liver cirrhosis: A preliminary, prospective, open-label study. Hepatol. Res. 2013;43(5):452-458. DOI: 10.1111/j.1872-034X.2012.01092.x

Koeth R.A., Wang Z., Levison B.S., Buffa J.A., Org E., Sheehy B.T., Britt E.B., Fu X., Wu Y., Li L., Smith J.D., DiDonato J.A., Chen J., Li H., Wu G.D., Lewis J.D., Warrier M., Brown J.M., Krauss R.M., Tang W.H., Bushman F.D., Lusis A.J., Hazen S.L. Intestinal microbiota metabolism of L-carnitine, a nutrient in red meat, promotes atherosclerosis. Nat. Med. 2013;19(5):576-585. DOI: 10.1038/nm.3145

Kushnerova N.F., Fedoreev S.A., Fomenko S.E., Sprygin V.G., Kulesh N.I., Mishchenko N.P., Veselova M.V., Momot T.V. Hepatoprotective properties of isoflavonoids from roots of Maackia amurensis on experimental carbon tetrachloride-induced hepatic damage. Eksp. Klin. Farmakol. 2014;77(2):26-30.

Kwon S.C., Kim Y.B. Antifibrotic activity a fermentation filtrate of Ganoderma lucidum. Lab. Anim. Res. 2011;27(4):369-371. DOI: 10.5625/lar.2011.27.4.369

Lieber C.S. Alcoholic fatty liver: its pathogenesis and mechanism of progression to inflammation and fibrosis. Alcohol. 2004;34(1):9-19. DOI: $10.1016 /$ j.alcohol.2004.07.008
Malaguarnera M., Risino C., Cammalleri L., Malaguarnera L., Astuto M., Vecchio I., Rampello L. Branched chain amino acids supplemented with L-acetylcarnitine versus BCAA treatment in hepatic coma: a randomized and controlled double blind study. Eur. J. Gastroenterol. Hepatol. 2009;21(7):762-770. DOI: 10.1097/ MEG.0b013e328309c791

Nelson D.L., Cox M.M. Lehninger Principles of Biochemistry. W.H. Freeman; Fifth Edition, 2008.

Nicholas P.C., Kim D., Crews F.T., Macdonald J.M. 1H NMR-based metabolomic analysis of liver, serum, and brain following ethanol administration in rats. Chem. Res. Toxicol. 2008;21(2):408-420. DOI: $10.1021 / \mathrm{tx} 700324 \mathrm{t}$

Psychogios N., Hau D.D., Peng J., Gui A.C., Mandal R., Bouatra S., Sinelnikov I., Krishnamurthy R., Eisner R., Gautam B., Young N., Xia J., Knox C., Dong E., Huang P., Hollander Z., Pedersen T.L., Smith S.R., Bamforth F., Greiner R., McManus B., Newman J.W., Goodfriend T., Wishart D.S. The human serum metabolome. PLoS ONE. 2011;6(2):e16957. DOI: 10.1371/journal.pone.0016957

Romero-Martínez Á., Moya-Albiol L. Neuropsychology of perpetrators of domestic violence: the role of traumatic brain injury and alcohol abuse and/or dependence. Rev. Neurol. 2013;57(11):515-522.

Roslundet M.U., Tahtinen P., Niemitz M., Sjoholm R. Complete assignments of the ${ }^{1} \mathrm{H}$ and ${ }^{13} \mathrm{C}$ chemical shifts and $\mathrm{J}_{\mathrm{H}, \mathrm{H}}$ coupling constants in NMR spectra of d-glucopyranose and all d-glucopyranosyld-glucopyranosides. Carbohydr. Res. 2008;343(1):101-112. DOI: 10.1016/j.carres.2007.10.008

Shayakhmetova G.M., Bondarenko L.B., Kovalenko V.M., Kharchenko O.L., Bohun L.I., Omelchenko Y.O. Multiparameter rodent chronic model for complex evaluation of alcoholism-mediated metabolic violations. J. Basic Clin. Physiol. Pharmacol. 2015;26(1):43-51. DOI: $10.1515 / \mathrm{jbcpp}-2013-0163$

Shevelev O.B., Akulov A.E., Dotsenko A.S., Kontsevaya G.V., Zolotykh M.A., Gerlinskaya L.A., Veprev S.G., Goryachkovskaya T.N., Zhukova N.A., Kolchanov N.A., Pel'tek S.E., Moshkin M.P. Neurometabolic effect of Altaian fungus Ganoderma lucidum (Reishi mushroom) in rats under moderate alcohol consumption. Alcohol.: Clin. Exp. Res. 2015;39(7):1128-1136. DOI: 10.1111/acer.12758

Shi Y., Sun J., He H., Guo H., Zhang S. Hepatoprotective effects of Ganoderma lucidum peptides against D-galactosamine-induced liver injury in mice. J. Ethnopharmacol. 2008;117(3):415-419. DOI: 10.1016/j.jep.2008.02.023

Shieh Y.H., Liu C.F., Huang Y.K., Yang J.Y., Wu I.L., Lin C.H., Li S.C. Evaluation of the hepatic and renal-protective effects of Ganoderma lucidum in mice. Am. J. Chin. Med. 2001;29(3/4):501-507. DOI: 10.1142/S0192415X01000526

Siler S.Q., Neese R.A., Christiansen M.P., Hellerstein M.K. The inhibition of gluconeogenesis following alcohol in humans. Am. J. Physiol. 1998;275(5 Pt 1):E897-E907.

Tang W.H., Wang Z., Levison B.S., Koeth R.A., Britt E.B., Fu X., Wu Y., Hazen S.L. Intestinal microbial metabolism of phosphatidylcholine and cardiovascular risk. N. Engl. J. Med. 2013;368(17):1575-1584. DOI: 10.1056/NEJMoa1109400

Wang M.Y., Liu Q., Che Q.M., Lin Z.B. Effects of total triterpenoids extract from Ganoderma lucidum (Curt: Fr) P Karst (Reishi mushroom) on experimental liver injury models induced by carbon tetrachloride or D-galactosamine in mice. Acta Pharmaceut Sin. 2000;35:326-329.

Wen H., Kang S., Song Y., Song Y., Sung S.H., Park S. Differentiation of cultivation sources of Ganoderma lucidum by NMR-based metabolomics approach. Phytochem. Anal. 2010;21(1):73-79. DOI: 10.1002/pca. 1166

Wu Y.W., Fang H.L., Lin W.C. Post-treatment of Ganoderma lucidum reduced liver fibrosis induced by thioacetamide in mice. Phytother. Res. 2010;24(4):494-499. DOI: 10.1002/ptr.2949

Zhao H.B., Lin S.Q., Liu J.H., Lin Z.B. Polysaccharide extract isolated from ganoderma lucidum protects rat cerebral cortical neurons from hypoxia/reoxygenation injury. J. Pharmacol. Sci. 2004;95(2):294298. DOI: $10.1254 /$ jphs.SC0040011 